Asian Journal of Engineering and Applied Technology ISSN 2249-068X Vol. 7 No. 1, 2018, pp.66-69

(C) The Research Publication, www.trp.org.in

\title{
Static and Fatigue Analysis of Carbon Epoxy Reinforced Composite Leaf Spring
}

\author{
Chatwant Singh Pandher ${ }^{1}$, Gurinder Singh Brar ${ }^{2}$ and Tejeet Singh ${ }^{3}$ \\ ${ }^{1}$ Ph.D Research Scholar, I. K. Gujral Punjab Technical University, Kapurthala, Punjab, India \\ ${ }^{2}$ Department of Mechanical Engineering, Guru Nanak Dev Engineering College, Ludhiana, Punjab,India \\ ${ }^{3}$ Mechanical Engineering Department, SBS State Technical Campus, Ferozepur, Punjab,India \\ E-Mail: chatwantpandher@gmail.com
}

\begin{abstract}
Different fields of mechanical, automobile, aerospace, electronics and communication engineering uses composite material. The automobile industries have shown great interest to change traditional use of steel leaf spring with light weight composite leaf spring with same strength. This research paper presents the general study, fabrication, static and fatigue analysis on carbon epoxy composite leaf spring. A rear leaf spring of Tata Ace (mini truck) made of material EN45 spring steel was selected as practical application. Hand Lay-up technique was used to make a carbon epoxy leaf spring. A single carbon epoxy composite leaf spring is compared with EN45 steel leaf spring. Static test was performed on both steel spring and composite spring from initial load of $1000 \mathrm{~N}$ to full load of $5400 \mathrm{~N}$. Results shows that deflection of carbon epoxy composite leaf spring is $14 \%$ less as compared to the steel leaf spring which means increase in stiffness. Also fatigue life of composite leaf spring is more than desire 100000 cycles.
\end{abstract}

Keywords: Leaf Spring, Static Test, Fatigue Test, Carbon Fiber, Epoxy Resin

\section{INTRODUCTION}

Innovations in automobile tend to modify the existing products or replacing old products by new and advanced material products. Also needs of the natural resource conservation and energy, the automobile manufacturers have been attempting to reduce the weight of the vehicle in recent years [1]. A suspension system of a vehicle is also an area where these innovations are carried out regularly. More efforts are taken in order to increase the comfort of the user. Appropriate balance of comfort riding qualities and economy in the manufacturing of leaf springs becomes an obvious necessity. Further, introduction of the composite materials made it possible to reduce the weight of the leaf springs without any reduction of load carrying capacity and stiffness. Many studies were conducted on the application of the composite materials for automobile suspension system (leaf springs) [2, 3]. Compared to steel spring, the composite leaf spring is found to have $64.95 \%$ higher stiffness and $126.98 \%$ higher natural frequency than that of existing steel leaf springs [2].Multi leaf springs used in the automotive vehicles normally consist of full length leaves and graduated length leaves. Finite element analysis using ANSYS software has been carried on conventional leaf springs to determine the safe stress and pay loads and it is observed that inner side of eye sections [4].Composite mono leaf springs were manufactured with integral eye and tested under static loading condition. Also fatigue life prediction was done to ensure a reliable number of life cycles. Leaf springs were modelled in conventional way and simulated for the kinematic and dynamic comparatives [5]. An artificial genetics approach for the design optimisation of the composite leaf springs were conducted [6]. Static testing and finite element analysis have been conducted to obtain the characteristics of the spring. Load - deflection curves and strain measurement as a function of loads for the three design tested have been plotted for the comparison with the FEA predicted values [7]. Suspension leaf spring is one of the potential items for weight reduction in automobile as it accounts for ten to twenty percent of the unsprung weight, which is considered to be the mass not supported by the leaf spring. So, composite materials are now used in automobile industries to take place of metal parts. As the composite materials have more elastic strain energy storage capacity and high strength-to-weight ratio as compared to those of steel spring. Composite materials offers opportunity for substantial weight saving. Spring is design to absorb and store energy and then release it hence strain energy of material and shape becomes major factors in designing the spring. The spring allows the movement of wheel over obstacles and then after returns the wheel to its normal position.Present study attempts to investigate possibility to manufacture composite leaf spring and then perform static and fatigue analysis. The rear leaf spring of Tata Ace (mini truck) made of EN45 spring steel is considered as experimental application. Leaf spring with Carbon epoxy reinforced fiber composite is manufactured by hand layup technique. Fatigue life and deformation under different load of composite leaf spring are performed as per the standards - IS 1135: 1995 Leaf Springs assembly for automobiles[8] and SAE HS - J788 - Manual on Design and Application of Laminated Springs.

\section{EXPERIEMENTAL WORK}

\section{A. Leaf Spring Fabrication Steps}

1. Development of Pattern: For fabrication of composite leaf spring the pattern is required. The pattern is made up of wood. 


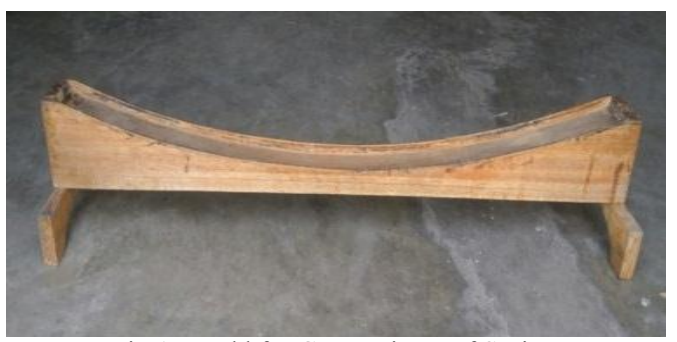

Fig.1 Mould for Composite Leaf Spring

2. The Preparation of Matrix (Epoxy): In preparation of the mixture, two solutions were used named epoxy resin and hardener. The ratio is 1:5. Resin hardener blend is blended completely and mixed, till a gel like appearance happen.

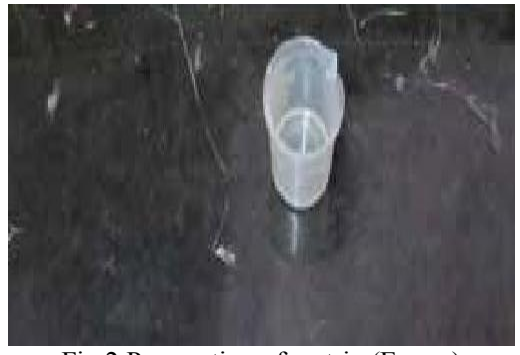

Fig.2 Preparation of matrix (Epoxy)

3. Cleaning and Polishing of Mould: To avoid sticking of the composite with resin after curing, the mould is polished with wax.

4. Cutting of Fibers: The material is carbon fiber. The fiber is available with sheet format. With the help of scissor fiber sheet is cut down. The dimensions for cutting lamina are $960(\mathrm{~mm}) \times 60(\mathrm{~mm})$.

5. Laying of laminas: After the arrangement of gum hardener blend it is connected on the surface of the material with a specific end goal to wet it. The wetting is done similarly by moving hand roller on the fabric surface with the goal that fiber is not separated from the material. Laying of laminas is done to the thickness required of the overlay; there is a need to build a $14 \mathrm{~mm}$ thickness cover then 42 laminas be layered up on the grounds that the thickness of every lamina is $0.24 \mathrm{~mm}$.

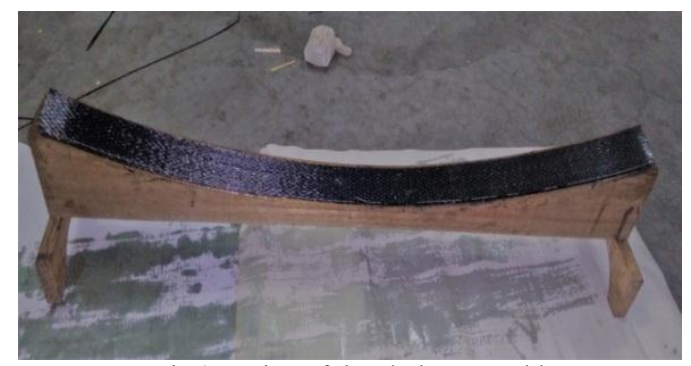

Fig.3 Laying of the cloth on mould

6. Curing: At last after the way towards laying the laminas to the mould and permitted at room temperature for $72 \mathrm{hrs}$. After that the part is discharged from the mould precisely without making any harm to the segment.

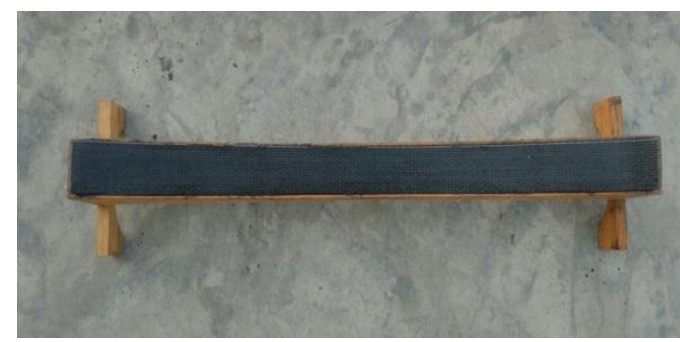

Fig.4 Mould left for curing

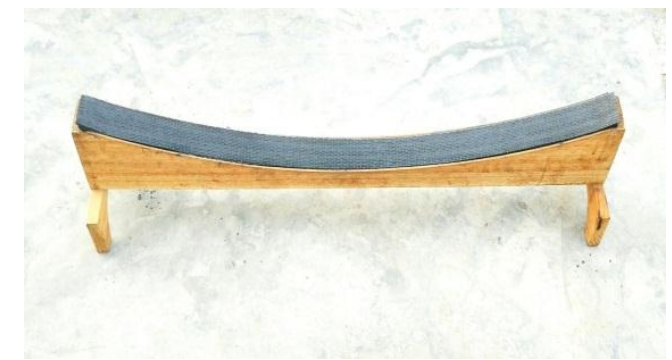

Fig. 5 Mould after 72 hour of curing

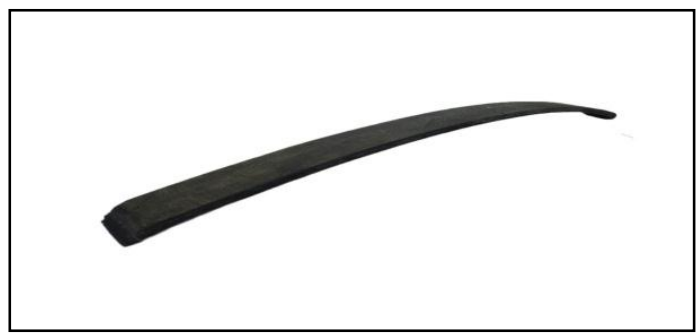

Fig.6 Finished carbon epoxy composite leaf spring

\section{RESULTS AND DISCUSSION}

Composite leaf spring is prepared by Hand Layup Technique. It is assumed that composite material will have better mechanical properties and less weight other than steel leaf spring. Static and fatigue test is performed on both composite leaf spring and steel spring.

\section{A. Static Test}

The electro-hydraulic leaf spring test rig is used to perform static test on steel spring and composite leaf spring. EN45 steel spring is use in Tata ace mini truck. The mechanical properties of EN45 material are given in Table I.

TABLE I MECHANICAL PROPERTIES OF EN 45 STEEL SPRING

\begin{tabular}{|c|c|c|c|c|}
\hline Properties & $\begin{array}{c}\text { Young's } \\
\text { Modulus, } \\
\mathbf{E}\left(\mathbf{N} / \mathbf{m m}^{2}\right)\end{array}$ & $\begin{array}{c}\text { Poisons } \\
\text { Ratio }\end{array}$ & $\begin{array}{c}\text { Tensile } \\
\text { Strength } \\
\mathbf{( M P a )}\end{array}$ & $\begin{array}{c}\text { Density } \\
\mathbf{( k g / \mathbf { m } ^ { 3 } )}\end{array}$ \\
\hline $\begin{array}{c}\text { Material } \\
\text { EN45 }\end{array}$ & 204000 & 0.30 & 621 & 7850 \\
\hline
\end{tabular}

The total weight of Tata ace is $885 \mathrm{~kg}$ and Gross vehicle weight of vehicle is $1550 \mathrm{~kg}$.The present steel spring of material EN45 include the $915 \mathrm{~mm}$ length, $57 \mathrm{~mm}$ width, 7 $\mathrm{mm}$ thickness. To find the deflection, load apply on the spring is from initial load of $1000 \mathrm{~N}$ to final load of $5400 \mathrm{~N}$. 
In hydraulic test ring, the plunger is move to desired height so that fixture can be fixed. Leaf spring is mounted with help of special fixture. The load is applied at the spring centre and spring deflection is recorded at different loads. Final Deflection values of composite spring is $14 \%$ less than steel spring deflection value which means more stiffness in the composite leaf spring. Load deflection curve under different loads shown in fig.7.

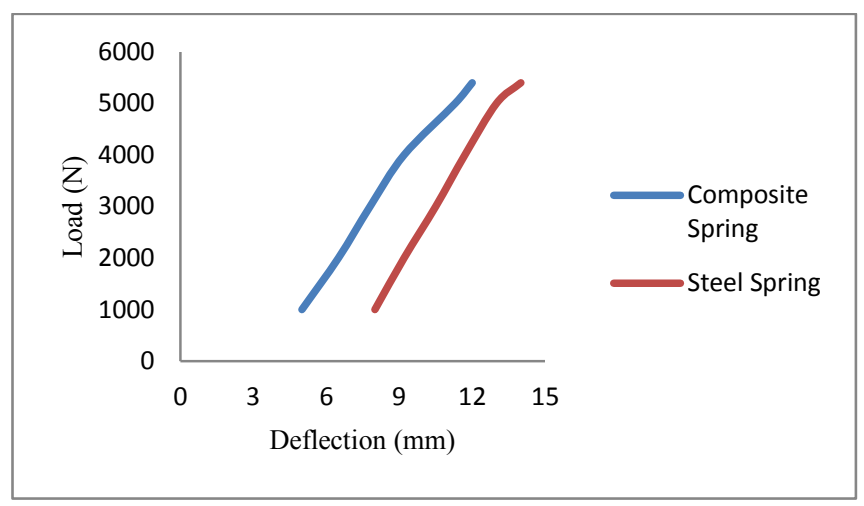

Fig.7 Load deflection curve for steel spring and composite spring.

\section{B. Fatigue Strength}

Fatigue test is important to find the maximum load that a sample can endure for a specified number of cycles. The main reasons of fatigue failure are number of cycle, range of stress and local stress. To find out the fatigue strength, Fatigue test performed on steel spring and composite leaf spring separately. A long time is required to find the fatigue strength of leaf spring.

\section{Fatigue Test of Steel Leaf Spring}

Hydraulic load test machine is used to know fatigue strength which include stroke of $0-150 \mathrm{~mm}$. Fatigue strength of leaf spring must be stand above the 100000 cycle. The leaf spring is placed on to hydraulic load machine. [8][9] After initial starting of machine, cycle of loading and unloading repeat until the end of the test reach. The Hydraulic test rig initial deflection is $60 \mathrm{~mm}$ and the initial stress is $203 \mathrm{MPa}$. Final stress of the spring is $110 \mathrm{~mm}$ and the stress is 304 $\mathrm{MPa}$. It is investigated that fatigue life of the steel spring was above to 100000 cycles.

\section{Fatigue Analysis of Carbon Epoxy Composite Leaf Spring}

To find the fatigue strength of carbon epoxy composite leaf spring similar hydraulic test rig machine is used and similar procedure is adopted. Load applied from initial load of 1000 $\mathrm{N}$ to $5400 \mathrm{~N}$ to find the fatigue strength. Hydraulic test machine set to operate for a deflection of $70 \mathrm{~mm}$ and 25 strokes/min. The maximum and minimum stress value obtain during cycle of the leaf spring are $77 \mathrm{MPa}$ and 105 MPa. During first 20000 cycles no any crack formation seen in the composite leaf spring. The maximum load apply on the composite leaf spring is $5400 \mathrm{~N}$ and time taken is 16 hours. Hydraulic test rig is use to perform fatigue test shown in fig.9.

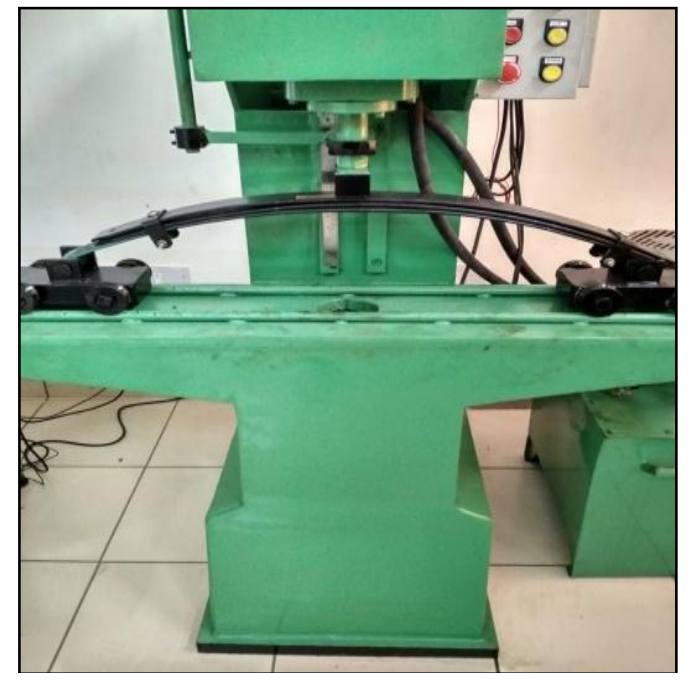

Fig.8 Fatigue testing of steel spring

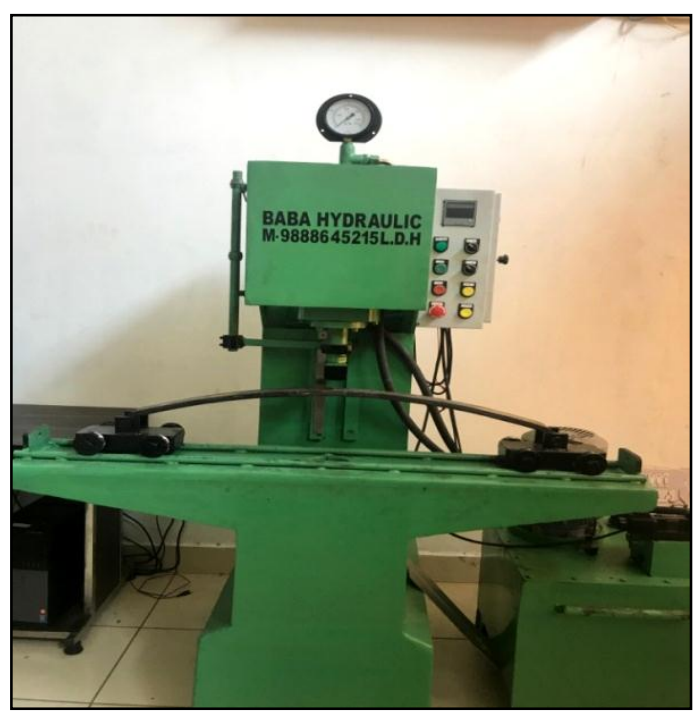

Fig.9 Fatigue testing of composite leaf spring

Further, Hwang and Han analytical model is used to know the number of fatigue cycle to failure for the composite leaf spring. Hwang and Han has given a relation $N=\{B(1-r)\}^{1 / c}$ , where $\mathrm{B}$ and $\mathrm{C}$ are the constants, value of $\mathrm{B}=10.33$ and $\mathrm{c}$ $=0.14012, \mathrm{~N}=$ no of cycle to failure and $\mathrm{r}=$ stress level value which is equal to $\sigma_{\max } / \sigma_{\mu}: \sigma_{\max }=$ maximum stress and $\sigma_{\mu}=$ ultimate tensile strength.[10]The fatigue life of carbon epoxy composite leaf spring is calculated by applied different stress levels. The results are obtained by analytical bases and plotted on $\mathrm{S} / \mathrm{N}$ curve. It is analysed that composite based leaf spring withstand more than 100000 cycle under the stress level 0.5 . It is estimated that crack formation may be occur only after 100000 cycles. 


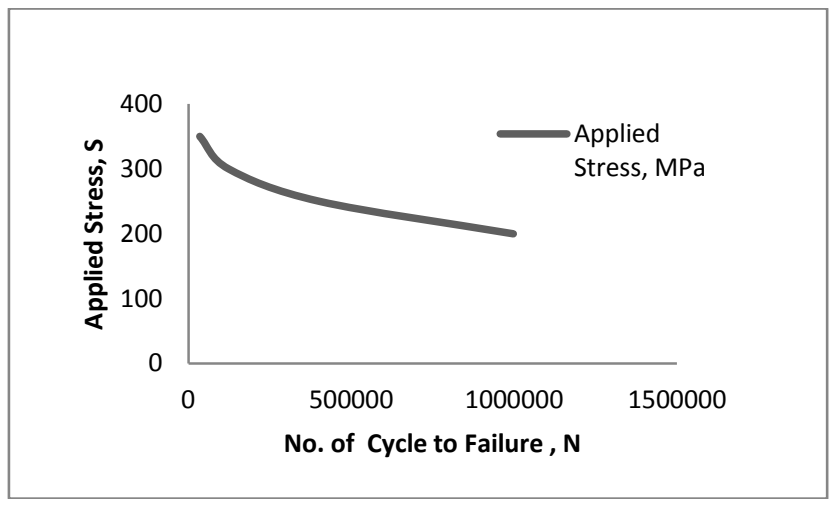

Fig.10 S/N curve for composite leaf spring

\section{CONCLUSION}

The carbon epoxy composite based leaf spring is successfully manufactured via hand layup technique. The leaf spring of composite is lighter in weight as compared to conventional steel leaf spring with similar design specification. The carbon epoxy composite based composite leaf spring is found deflection $14 \%$ less to the deflection values of existing steel spring values which means increase in stiffness. And fatigue analysis of steel spring and composite spring is carried out. Fatigue life cycle of steel spring and composite leaf spring is more than design value 100000 cycles. It is concluded that carbon epoxy composite leaf spring is an effective replacement for the existing steel spring used in automobile vehicles.

\section{ACKNOWLEDGMENTS}

Authors would like to thank I.K. Gujral Punjab Technical University, Kapurthata (Punjab), India for providing them the opportunity to carry out this research work.

\section{REFERENCES}

[1] H. A. Al-Qureshi, "Automobile leaf spring from composite materials", Journal of Material Processing Technology, Vol. 118, pp. 58-61, 2001.

[2] S. Kumar and S. Vijayarangan, "Analytical and experimental studies on fatigue life prediction of steel and composite multi-leaf springs for light passenger vehicles using life data analysis", Journal of Material Processing Technology, Vol. 13, pp.141-146, 2007.

[3] R. L. Daugherty, "Composite leaf springs in heavy truck applications", International conference on composite material proceedings of Japan US conference, Tokyo, pp. 529-538, 1981.

[4] G. Harinath and V. Gowd, "Static analysis of leaf springs", International Journal of Engineering Science and Technology, Vol. 4, pp. 3794-3803, 2012.

[5] I. Rajendran and S. Vijayarangan, "Optimal design of composite leaf springs using genetic algorithm," Computer and Structures, Vol. 79, pp. 1121-1129, 2001.

[6] M. M. Shokrieh and D. Rezaei, "Analysis and optimization of a composite leaf spring", Composite structures, Vol. 60, pp. 317-325, 2003.

[7] J. P. Hou and J. Y. Cherrualt, "Evolution of the eye-end design of a composite leaf spring for heavy axle loads", Composite Structures, Vol. 78, No. 3, pp. 351-358, 2006.

[8] IS 1135.1995: Springs- Leaf Springs assembly for Automobiles

[9] Spring Design Manual. Design and Application of Leaf Springs, AE11, Society of Automotive Engineer HS-788, 1990.

[10] W. Hawang and K. S. Han, "Fatigue of composites - fatigue modulus concept and life prediction", Journal of Composite Materials, Vol. 20, pp. 154-165, 1986. 